International Journal of Social Science And Human Research

ISSN(print): 2644-0679, ISSN(online): 2644-0695

Volume 04 Issue 12 December 2021

DOI: $10.47191 / \mathrm{ijsshr} / \mathrm{v} 4-\mathrm{i} 12-37$, Impact factor-5.586

Page No: 3717-3722

\title{
Different Effects of Live Demonstration and Video Demonstration Learning Models on the Performance of the Tennis Service Biomechanics Review from Eye-Hand Coordination
}

\author{
Bilqis Maqbulatullah', M. Furqon Hidayatullah ${ }^{2}$, Sapta Kunta Purnama $^{3}$, Rumi Iqbal Doewes ${ }^{4}$ \\ ${ }_{1,2,3,4}$ Postgraduate in Sports Science, Sebelas Maret University, Indonesia \\ Orcid id: 0000-0001-9922-2719¹, 0000-0001-8862-5862², 0000-0001-7198-13853 , 0000-0003-1048-3934
}

\begin{abstract}
This study aims to determine: (1) The difference in the effect of live demonstration and video demonstration exercise models on the biomechanics performance of court tennis service, (2) Differences in the performance of tennis service biomechanics between players who have high and low eye-hand coordination, (3) Effect of interaction between exercise model and eye-hand coordination on the performance of tennis service biomechanics. This study used an experimental method with a $2 \mathrm{x}$ 2 factorial design. The population in this study were all 12 players of the male KKO SMPN 1 Surakarta. The sampling technique used is saturated sampling, the size of the sample taken is 12 players. The data analysis technique in this study used ANOVA. Before being tested with ANOVA, first using the prerequisite test of data analysis with sample normality test (Lilliefors test with $=0.05 \%$ ) and homogeneity test of variance (Bartlett test with $=0.05 \%$ ). Based on the results of the study, it can be concluded as follows: (1) there is a difference in the effect of live demonstration and video demonstration exercise models on the performance of tennis service biomechanics. The effect of the live demonstration exercise model is better than the video demonstration ex ercise model, (2) there are differences in the biomechanics performance of court tennis service between players who have high and low eye-hand coordination. The biomechanics performance of court tennis services on players who have high eye-hand coordination is better than players who have low eye-hand coordination, (3) there is an interaction between training models and eye-hand coordination on the biomechanics performance of court tennis services. Players who have high eye-hand coordination are more suitable if given a live demonstration exercise model. Players who have low eye-hand coordination are more suitable if given a video demonstration exercise model.
\end{abstract}

KEYWORDS: Live Demonstration, Video Demonstration Exercise, Eye-Hand Coordination, Tennis Court

\section{INTRODUCTION}

Court tennis is an intermittent sport in which players need a mix of physical components, such as linear sprints and changes in direction of speed, agility, muscle power, and cardiovascular fitness to achieve high levels of performance (Fernandez, et al., 2021). Tennis players are required to make a high number of strokes every practice or match with strong shots including serves and groundstrokes. This sport has developed with many tennis matches being held. Field tennis requires agile movements in carrying out basic techniques, so every player needs to master the technique and have a good physique. Technical and physical improvement in playing tennis needs to be done with repeated and gradual exercises. The level of technical and tactical decision making in court tennis has a very important impact on the outcome of the game (Li, et al., 2021). Field tennis requires skills in which there are elements of physical conditions that need to be trained such as strength, endurance, coordination, balance, explosive power, and others. According to (Türker and Yüksel,. 2021) that functional training increases speed, endurance, strength, explosive strength, flexibility and agility.

The exercise intervention showed an increase in the physical fitness component (Ferrari, et al., 2021). The components of physical fitness in question are endurance, strength, agility, speed, flexibility, coordination, balance, accuracy, reaction speed. This component can be referred to as an element of physical condition which trains this element an athlete can obtain peak performance. Based on the training pyramid, physical is the first thing to consider before paying attention to technical, tactical, and mental training. Tennis performance is the result of the interaction of anthropometric, physiological, psychological, tactical and technical characteristics (Kolman, et al., 2021). The achievement of peak performance is supported and influenced by the basic tennis techniques mastered by the players. Service in court tennis needs to be mastered by players because it is included in basic techniques. Good service requires training according to the player's physicality. The training begins with basic skills training, it is intended that later the performance of basic skills has been mastered correctly. 


\section{Different Effects of Live Demonstration and Video Demonstration Learning Models on the Performance of the Tennis Service Biomechanics Review from Eye-Hand Coordination}

Service should be considered the first attack, not just the start of the game. However, this statement has not been implemented by the KKO players of SMPN 1 Surakarta. KKO SMPN 1 Surakarta is a Special Class for Sports at SMPN 1 Surakarta which is devoted to the sport of tennis. Based on the observations of the researchers, the male KKO players at SMPN 1 Surakarta lacked basic service techniques such as the arm swing strength that was not maximized, causing the ball to not enter the opponent's service box, or the service ball to enter the wrong opponent's box, besides that there was also a foot violation when do service. KKO men's players take steps forward when serving so that the player's feet enter the tennis court line. Therefore the player does not earn points and causes the opposing player to receive points. With these weaknesses, the service technique of the male KKO players at SMPN 1 Surakarta needs to be improved in order to serve properly.

The training model used at this time has not been able to improve tennis service skills. Tennis training model as a goal so that training can be organized and planned in teaching athletes to learn the basic knowledge and skills of tennis (Cheng, et al., 2021). Court tennis coaches need to use the right training model in providing service training. Therefore, a trainer needs to understand the science that supports the training process. Various sciences related to sports include exercise physiology, sports biomechanics, sports pedagogy, sports sociology, sports psychology and sports health. Science in sports can be used as a reference or basis for developing appropriate, effective, and efficient training programs. The types of exercise models that can be used to improve the service ability of tennis courts include live demonstration and video demonstration exercise models. The live demonstration exercise model is carried out with a demonstration given directly from the tennis service movement, while the video demonstration exercise model is carried out using a tennis service stroke video.

The tennis service movement phase starts from the preparation and swing stages, point of contact, and follow-up movements. Seeing the complexity of the movements that must be done during service, special supervision is needed so that it can make it easier and faster to master service techniques. In this modern era, analysis related to movement can be done through the study of biomechanics. From a biomechanics point of view, the serve movement is divided into three stages (preparation, acceleration and follow-through) including eight stages (start, release, loading, cocking, acceleration, contact, deceleration and finish) (Pay, et al., 2021). With the study of biomechanics, it will be able to analyze the movement of the service technique then the results of the analysis can be used as a contribution in fostering performance, especially movement efficiency, as well as producing factors that can hinder the efficiency of the tennis service technique movement.

The success of playing tennis is also influenced by the player's personal factors, both internal and external. It is impossible to completely predict which individual will develop into a top-level tennis player based on talent alone (one of the internal factors), because there are many external factors that significantly influence the development and achievement of top-level tennis players (Oršolić, et al., 2021). ). Internal conditions are factors that exist in individuals such as physical abilities, where physical abilities are related to hand-eye coordination. Eye-hand coordination affects movement training, so this is the main requirement in achieving the peak performance of a tennis player to master court tennis service.

Other factors such as position and movements that have been made need to be considered by players. Players can correct and control their own movements if they are aware of the position and movements that have been made, so this factor becomes important when undergoing a match. Classification of high and low eye-hand coordination affects the mastery of tennis service techniques. The difference in eye-hand coordination is a decisive consideration in mastering the movement of court tennis service. The difference in eye-hand coordination possessed by players is a consideration in determining the training model according to the characteristics of each player so that they can achieve maximum training results according to their respective potential. Eye-hand coordination is the ability of the visual system to analyze and provide instructions for information captured by the eye to the upper limbs which are in charge of carrying out regular actions, such as catching or throwing objects (Buzescu, et al., 2021).

Based on the background that has been described, it is known that the training model has an effect on achieving player achievement. The live demonstration and video demonstration exercise models have not yet been implemented. Therefore, this study aims to determine the difference in the effect of live demonstration and video demonstration exercise models on the biomechanics performance of court tennis services in terms of eye-hand coordination.

\section{METHODS}

The research method uses an experiment with a 2x2 factorial design. A factorial experiment is an experiment in which almost or all levels of a factor are combined or crossed with all levels of every other factor in the experiment. The research sample consisted of 12 players who were male players from KKO SMPN 1 Surakarta. Data Collection Techniques and Instruments using Eye-hand Coordination Test, Tennis Field Service Test. The data analysis technique used was two-way analysis of variance (ANAVA) at = 0.05 .

\section{RESULTS AND DISCUSSION}

The description of the results of the analysis of the biomechanics of tennis service performance data carried out according to the group is compared and presented in the form of a table as follows: 
Different Effects of Live Demonstration and Video Demonstration Learning Models on the Performance of the Tennis Service Biomechanics Review from Eye-Hand Coordination

Table 1. Data Description of the Performance Test Results of Tennis Field Service Biomechanics for Each Group Based on the Use of Exercise Models and Level of Eye-Hand Coordination

\begin{tabular}{|c|c|c|c|c|c|}
\hline Treatment & $\begin{array}{l}\text { Eye-Hand } \\
\text { Coordination Level }\end{array}$ & Statistics & $\begin{array}{l}\text { Preliminary } \\
\text { Test Results }\end{array}$ & $\begin{array}{l}\text { Final Test } \\
\text { Results }\end{array}$ & Enhancement \\
\hline \multirow{6}{*}{$\begin{array}{l}\text { Live } \\
\text { Demonstration } \\
\text { Practice } \\
\text { Model }\end{array}$} & \multirow{3}{*}{ high } & Amount & 3827 & 4395 & 568 \\
\hline & & Average & 1275.548 & 1464.904 & 189.356 \\
\hline & & SD & 42.325 & 46.543 & 29.799 \\
\hline & \multirow{3}{*}{ low } & Amount & 4108 & 4253 & 145 \\
\hline & & Average & 1369.348 & 1417.638 & 48.290 \\
\hline & & SD & 54.636 & 38.368 & 30.492 \\
\hline \multirow{6}{*}{$\begin{array}{l}\text { Model } \\
\text { Exercise } \\
\text { Video } \\
\text { Demonstration }\end{array}$} & \multirow{3}{*}{ high } & Amount & 4020 & 4106 & 86 \\
\hline & & Average & 1339.982 & 1368.798 & 28.815 \\
\hline & & SD & 114.443 & 113.206 & 11.897 \\
\hline & \multirow{3}{*}{ low } & Amount & 3731 & 3961 & 230 \\
\hline & & Average & 1243.540 & 1320.241 & 76.701 \\
\hline & & SD & 66.324 & 111.315 & 50.999 \\
\hline
\end{tabular}

Based on table 2, the average initial test results for the biomechanics performance of the tennis service group of players who have high eye-hand coordination trained using the live demonstration exercise model is 1275,548 , the standard deviation is 42,325. The average of the final test results of the tennis service biomechanics performance of the group of players who have high eye-hand coordination trained using the live demonstration exercise model is 1464,904, the standard deviation is 46,543 . The improvement in the results of the biomechanics performance test of tennis service groups of players who have high eye-hand coordination trained using a live demonstration exercise model is 189,356 , the standard deviation is 29,799 .

The average results of the initial test of the tennis service's biomechanics performance group of players who had low eyehand coordination trained using the live demonstration exercise model was 1369,348, the standard deviation was 54,636. The average result of the final test of the biomechanics performance of the tennis service group of players who have low eye-hand coordination trained using the live demonstration exercise model is 1417.638 , the standard deviation is 38.368 . The improvement in the results of the biomechanics performance test of tennis service groups of players who have low eye-hand coordination trained using a live demonstration exercise model is 48,290 , the standard deviation is 30,492 .

The average of the initial test results for the biomechanics performance of the tennis service group of players who have high eye-hand coordination trained using the video demonstration exercise model is 1339,982 , the standard deviation is 114,443 . The average result of the final test of the biomechanics performance of the tennis service group of players who have high eyehand coordination trained using the video demonstration exercise model is 1368,798 , the standard deviation is 113,206 . The improvement in the results of the field tennis service biomechanics performance test of a group of players who have high eyehand coordination trained using a video demonstration exercise model is 28,815 , the standard deviation is 11,897 .

The average of the initial test results for the biomechanics performance of the tennis service group of players who have low eye-hand coordination trained using the video demonstration exercise model is 1243,540 , the standard deviation is 66,324 . The average of the final test results of the tennis service biomechanics performance of the group of players who have low eye-hand coordination trained using the video demonstration exercise model is 1320.241, the standard deviation is 111,315. The improvement in the results of the biomechanics performance test of tennis service groups of players who have low eye-hand coordination trained using a live demonstration exercise model is 76,701 , the standard deviation is 50,999 .

Table 2. Summary of the results of the analysis of variance of two factors

\begin{tabular}{llllll}
\hline Source of Variation & $\mathbf{d k}$ & $\mathbf{J K}$ & $\mathbf{R J K}$ & $\mathbf{F}_{\mathbf{0}}$ & $\mathbf{F}_{\mathbf{t}}$ \\
\hline Average & & & & & \\
Treatment & 1 & 88320.311 & 88320.311 & & \\
A & 1 & 13093.716 & 13093.716 & $11.485^{*}$ & 4.11 \\
B & 1 & 6511.906 & 6511.906 & $5.712^{*}$ & \\
AB & 1 & 26777.295 & 26777.295 & $23.488^{*}$ & \\
Mistake & 8 & 9120.294 & 1140.037 & & \\
\hline Total & 12 & 143823.522 & & & \\
\hline
\end{tabular}




\section{Different Effects of Live Demonstration and Video Demonstration Learning Models on the Performance of the Tennis Service Biomechanics Review from Eye-Hand Coordination}

The results of the ANOVA calculation in table 3 show that the price of Fo $=23,488$ and Ft $=4.11$, thus Fo $>$ Ft $(\mathrm{Fcount}$ is greater than Ftable). This means that there is an interaction between the exercise model with eye-hand coordination on the biomechanics performance of tennis service. This is evidenced by the value of Fcount $=23,488>$ Ftable $=4.11$.

Furthermore, the Newman-Keuls range test was conducted to determine whether there was a difference between the treatment averages. In detail can be seen in table 4 below.

Table 3. Summary of Newman-Keuls Range Test Results After Analysis of Variance

\begin{tabular}{cllllll}
\hline \multirow{2}{*}{$\mathrm{KP}$} & & $\mathrm{a}_{1} \mathrm{~b}_{2}$ & $\mathrm{a}_{2} \mathrm{~b}_{1}$ & $\mathrm{a}_{2} \mathrm{~b}_{2}$ & $\mathrm{a}_{1} \mathrm{~b}_{1}$ & \multirow{2}{*}{$\mathrm{RST}$} \\
\cline { 3 - 6 } & Average & 48.290 & 28.815 & 76.701 & 189.356 & \\
\hline $\mathrm{a}_{1} \mathrm{~b}_{2}$ & 48.290 & - & $19.475^{*}$ & $28.411^{*}$ & $141.066^{*}$ & 56.337 \\
$\mathrm{a}_{2} \mathrm{~b}_{1}$ & 28.815 & & - & 47.886 & 160.541 & 67.839 \\
$\mathrm{a}_{2} \mathrm{~b}_{2}$ & 76.701 & & & - & 112.655 & 74.857 \\
$\mathrm{a}_{1} \mathrm{~b}_{1}$ & 189.356 & & & - & \\
\hline Note: * significant at $\mathrm{p} 0.05$. & & &
\end{tabular}

Based on the hypothesis testing has resulted in two groups of analytical conclusions, namely: (a) there is a significant difference in influence between the main research factors, (b) there is a significant interaction between the main factors in the form of two-factor interaction. The group conclusions of the analysis can be further described as follows:

1. Differences in Influence between Live Demonstration Exercise Model and Video Demonstration on Biomechanics Performance of Tennis Field Service.

Based on the first hypothesis testing, it turns out that there is a significant difference in the effect between the group of players who received the live demonstration exercise model and the group of players who received the video demonstration exercise model on the biomechanics performance of the tennis service. The group of players who received the live demonstration exercise model had a better tennis service biomechanics performance than the group of players who received the video demonstration exercise model. From the figures generated in the data analysis, it shows that the ratio of the average percentage increase in the tennis service's biomechanics performance produced by the live demonstration exercise model is 66.065 higher than the video demonstration exercise model.

Demonstrations used in sports teaching and coaching are more useful than verbal instructions for skill acquisition (Lhuisset and Margnes., 2015). The live demonstration exercise model gives positive results in the implementation of the athlete's tennis court service. This is because the live demonstration is carried out with practice followed by a demonstration of the skills being taught and the sports facilities that have been provided (Simon, et al., 2020). It is different from the video demonstration which is only done by playing the video without being assisted by how to practice it so that it does not show the maximum improvement in the tennis service movement. In line with the research of (Palmer, et al., 2017) that specifically found no change in scores when a video demonstration was given as a substitute for a live demonstration. The researcher realized that this happened because of the need for further refinement or adjustment regarding the different focus of attention in the group.

2. Differences in Field Tennis Service Biomechanics Performance Between Players Who Have High and Low Eye-Hand Coordination.

Based on the second hypothesis testing, it turns out that there is a significant difference in the effect between groups of players who have high eye-hand coordination and low eye-hand coordination on the biomechanics performance of court tennis service. The group of players who have high eye-hand coordination has a tennis service biomechanics performance with an average increase of 109.09 higher than the group of players who have low eye-hand coordination with an average increase of 62.50 .

The development of coordination skills plays an important role in improving technical performance in sports that use rackets, sports that require speed and reaction (Gül and elik, 2021). Eye-hand coordination is the main capital to perform the biomechanics of tennis service performance. In line with this statement, (Patel and Bansal., 2018) also state that eye-hand coordination is an important characteristic in activities involving hitting the ball with a bat, depending on the visual system that is responsible for finding and fixing task-relevant objects. High eye-hand coordination is used by a player to perform court tennis service. Eye-hand coordination can support the successful achievement of tennis service biomechanics performance by controlling the technical movements performed more accurately. Players who have high eye-hand coordination have the ability to more quickly master the biomechanics performance of court tennis services than players who have low eye-hand coordination. The success of achieving the performance of tennis service biomechanics is influenced by the player's ability to perform movements in an integrated and harmonious manner. From the figures generated in the data analysis, it shows that the average comparison of the 


\section{Different Effects of Live Demonstration and Video Demonstration Learning Models on the Performance of the Tennis Service Biomechanics Review from Eye-Hand Coordination}

biomechanics performance of tennis service in players who have high eye-hand coordination is 46,590 which is higher than the group of players who have low eye-hand coordination. The results of this study are supported by the research of (Vorotnikova., 2021) that eye-hand coordination affects task performance where each learner is able to complete more trials overall and the experiments are carried out successfully during practice and have greater skill gains.

3. The Effect of Interaction Between Exercise Models and Eye-Hand Coordination on the Performance of Tennis Field Service Biomechanics.

Table 4. The summary of the results of the two-factor analysis of variance

\begin{tabular}{|c|c|c|c|c|c|c|}
\hline \multicolumn{3}{|c|}{ Factor } & \multicolumn{4}{|c|}{ A = Exercise Model } \\
\hline & & level & $\mathrm{a}_{1}$ & $a_{2}$ & Rerata & $a_{1}-a_{2}$ \\
\hline B & Eye-Hand & $b_{1}$ & 189.356 & 28.815 & 109.086 & 160.541 \\
\hline \multicolumn{2}{|r|}{ Coordination } & $\mathrm{b}_{2}$ & 48.290 & 76.701 & 62.496 & 28.411 \\
\hline \multicolumn{2}{|c|}{ Average } & & 118.823 & 52.758 & 85.791 & 46.590 \\
\hline \multicolumn{2}{|c|}{$b_{1}-b_{2}$} & & 141.066 & 47.886 & 66.065 & \\
\hline
\end{tabular}

Based on Figure above, that the shape of the line changes in the value of the biomechanics performance of the tennis service is not parallel or crossed. However, the line has a meeting point between the use of training models and eye-hand coordination. This means that there is a significant interaction between the two. The figure shows that eye-hand coordination has an influence on the performance of tennis service biomechanics. The effectiveness of the use of training models in the performance of tennis service biomechanics is influenced by the high and low eye-hand coordination of the players. Based on the results of the study, it turns out that players who have high eye-hand coordination with the live demonstration exercise model have a tennis service biomechanics performance of 189,356 better than players with high eye-hand coordination and receive treatment with a video demonstration exercise model of 28,815 .

Players who have low eye-hand coordination with the video demonstration exercise model have a tennis service biomechanics performance of 76,701 better than players with low eye-hand coordination and receive treatment with a live demonstration exercise model of 48,290. This is in line with the results of research by (Lhuisset and Margnes., 2015) that video demonstrations are more effective than live demonstrations for the initial acquisition of complex coordination in new players. This is due to the simplification of visual information. This simplification allows the player to identify more key elements that will guide him to the performance of his next task. This is also supported by the research of (Vrbik, et al., 2015) that the group that uses video demonstration benefits because it has a longer observation period to produce a number of task presentations.

\section{CONCLUSION}

Based on the results of the research and the results of data analysis that has been carried out, the following conclusions can be drawn:

1. There is a difference in the effect between the live demonstration and video demonstration exercise models on the biomechanics performance of the tennis service. The effect of the live demonstration exercise model is better than the video demonstration exercise model.

2. There is a difference in the biomechanics performance of court tennis service between players who have high and low eyehand coordination. The performance of tennis service biomechanics on players who have high eye-hand coordination is better than players who have low eye-hand coordination.

3. There is an interaction between the exercise model and eye-hand coordination on the performance of tennis service biomechanics.

a. Players who have high eye-hand coordination are more suitable if given a live demonstration exercise model.

b. Players who have low eye-hand coordination are more suitable if given a video demonstration exercise model.

\section{REFERENCES}

1) Buzescu, R., Nechita, F., and Cioroiu, S.G. The Relationship between Neuromuscular Control and Physical Activity in the Formation of the Visual-Psychomotor Schemes in Preschools. Sensors 2021, 21, 224. https://doi.org/10.3390/s21010224.

2) Cheng, P., Ming, D., Man, X., and Dai, D. Optimized Allocation of Tennis Teaching Resources Based on Big Data. Journal of Physics: Conference Series, 1744 (2021) 042138. doi:10.1088/1742-6596/1744/4/042138.

3) Fernandez, J.F., Ramon, M.M., Rosa, F.J.S., Gantois, P., Nakamura, F.Y., Rivas, D.S., and Granacher, U. Within-Session Sequence of the Tennis Serve Training in Youth Elite Players. Int. J. Environ. Res. Public Health $2021,18,244$. https://doi.org/10.3390/ijerph18010244. 
4) Ferrari, R., Carpes, L.O., Domingues, L.B., Jacobsen, A., Frank, P., Jung, N., Santini, J., and Fuchs, S.C. Effect Of Recreational Beach Tennis On Ambulatory Blood Pressure And Physical Fitness In Hypertensive Individuals (BAH Study): Rationale And Study Protocol. BMC Public Health (2021) 21:56. https://doi.org/10.1186/s12889-020-10117-5.

5) Gül, M., and Çelik, D. 2021. The Effect of Eight-Weeks Coordinatıon Training on Tennis and Motor Skills Performance on 8-10 Years Children. Pakistan Journal of Medical Health Sciences, 15(6), pp. 1578-1582. https://doi.org/10.53350/pjmhs211561578

6) Kolman, N.S., Huijgen, B.C.H., Visscher, C., and Gemser, M.T.E. The Value Of Technical Characteristics For Future Performance In Youth Tennis Players: A Prospective Study. PLoS ONE, 2021; 16(1): e0245435. https://doi.org/10.1371/journal.pone.0245435.

7) Lhuisset, L., and Margnes, E. 2015. The influence of live-vs. video-model presentation on the early ac- quisition of a new complex coordination. Physical Education and Sport Pedagogy, 20(5), pp.490-502. 10.1080/17408989.2014.923989.

8) Li, M., Li, Q., Li, Y., Cui, Y., Zhao, X., and Guo, L. Analysis of Characteristics of Tennis Singles Matches Based on 5G and Data Mining Technology. Hindawi Security and Communication Networks, Volume 2021, Article ID 5549309, 9 pages. https://doi.org/10.1155/2021/5549309.

9) Oršolić, M., Barbaros, P., and Novak, D. Talent in Sports Is Never Enough: A Preliminary Qualitative Data Analysis Qualitative Analysis. Collegium Antropologicum, Vol. 45 (2021) 1: 45-53. https://doi.org/10.5671/ca.45.1.6.

10) Palmer, K.K., Matsuyama, A.L., Irwin, J.M., Porter, J.M., and Robinson, L.E. 2017. The effect of attentional focus cues on object control performance in elementary children. Physical Education and Sport Pedagogy. http://dx.doi.org/10.1080/17408989.2017.1294667

11) Patel, B., and Bansal, P. 2018. Effect of 4 week exercise program on hand eye coordination. International Journal of Physical Education, Sports and Health, 5(4), pp. 81-84.

12) Pay, A.S., Gallego, R.M., Crespo, M., and Rivas, D.S. Key Physical Factors in the Serve Velocity of Male Professional Wheelchair Tennis Players. Int. J. Environ. Res. Public Health 2021, 18, 1944. https://doi.org/10.3390/ijerph18041944.

13) Simon, K.B., Adewole, R.S., and Muktar, S. Teaching Physical Education using Alternative Practical Methods before Demonstration: Implication to Physical Education Specialists. KIU Journal of Humanities, 2020; 5(1): 279-282. Kampala International University, ISSN: 2415-0843.

14) Türker, A., and Yüksel, O. The Effect Of Functional And Supportive Classic Strength Trainings In Basketball Players On Aerobic Strength, Dynamic Balance And Body Composition. Pedagogy of Physical Culture and Sports, 2021; 25(1): 4758. https://doi.org/10.15561/26649837.2021.0107.

15) Vorotnikova, M. 2021. Varying ball characteristics in learning tennis: effects of systematic progression and self-control. Thesis. Faculty of Southeastern Louisiana University in Partial Fulfillment of the Requirements for the Degree of Master of Science in Health and Kinesiology

16) Vrbik, I., Krističević, K., Sporiš, G., and Madić, D. 2015. The effects of live and video demonstration on the early acquisition of a new motor task. Journal of Science in Sport Exercise and Quality of Life, 7(2), pp. 30-40. 